\title{
Stein, Leventhal y el síndrome de ovarios poliquísticos
}

\section{Alfredo Jácome Roca, $M D, F A C P^{*}$}

*Internista-Endocrinólogo, miembro honorario de la ACE, de número de la Academia Nacional de Medicina de Colombia, Editor Emérito, revista MEDICINA, miembro activo, Sociedad Colombiana de Historia de la Medicina.

Fecha de recepción: 17/07/2018

Fecha de aceptación: 25/08/2018

$\mathrm{P}$ ara las primeras décadas del siglo XX ya existia un conocimiento aceptable sobre el ciclo menstrual, la funcion ovárica y las hormonas femeninas, en particular la potente actividad estrogénica de la orina de las mujeres embarazadas encontrada por serendipia en 1928 (Ascheim y Zondek). Papanicolau había demostrado la fluctuación hormonal durante el ciclo por sus citologías y en 1929 Doisy y Butenandt aislarían la estrona de la orina de las embarazadas y descubrirían la estructura de la estrona cristalizada, como un esteroide. Gracias a esto, los químicos aprendieron a manipular las moléculas esteroides, generando la posibilidad de su síntesis química. En 1935 se aisló el 17- beta estradiol, considerado el estrógeno natural más potente, lo que se logró a partir de 4 toneladas de ovarios porcinos; de esta enorme cantidad de tejido, solo se sacaron 10 mg de hormona cristalizada. Cinco años antes, Corner y Allen, en la Universidad de Rochester, descubrieron la progesterona.

En las dos décadas que siguieron a 1930, las hormonas sexuales, principalmente las estrogénicas, se utilizaron en el tratamiento de los síntomas menopáusicos, supresión de la lactancia después del parto, tratamiento del cáncer de la próstata y para evitar los desenlaces adversos del embarazo ${ }^{(1)}$.

Para 1935, durante una reunión de la Asociación Central de Obstetricia y Ginecología en Nueva Orléans, dos ginecólogos interesados en el tema de la infertilidad femenina (para esa época denominada esterilidad), los doctores Irving Freiler Stein y Michael Leventhal (figura 1) presentaron el estudio de siete mujeres con amenorrea, obesidad, hirsutismo e infertilidad. Los ovarios estaban agrandados entre 2 y 4 veces a la laparotomía, contenían de 20 a 100 quístes foliculares con 1 a 1,5 mm cerca a la superficie ovárica, que era de color gris nacarado, corteza hipertrófica y túnica engrosada y fibrótica. Ninguna paciente tuvo engrosamiento de la voz, los genitales externos eran normales en la mayoría, aunque en algunas había marcada hipertrofia de los labios menores con libido normal.

Estos médicos observaron que varias pacientes menstruaron después de que se les hizo la biopsia ovárica. Asi que resolvieron resecar entre medio y tres cuartos de sus ovarios, removiendo la parte de la corteza que contenia los quistes, suturando el hilio con catgut. En ambos ovarios la resección cuneiforme corrigió el trastorno menstrual y dos de las siete posteriormente quedaron embarazadas, dando a luz dos niños su primera paciente $^{(2)}$. Lo que empezó luego a llamarse "síndrome de poliquistosis ovárica" o "síndrome de Stein-Leventhal" empezó a ser reconocido por otros, y ampliado por los mismos autores que mostraron la efectividad de la resección ovárica en cuña para producir un embarazo en 47 mujeres.

El síndrome de ovarios poliquísticos (SOP) es la endocrinopatía femenina más comun, pues afecta entre el 5\% y el 15\% de las mujeres a nivel mundial. Para 1959, 24 años después de la publicación original, había ya 40 trabajos al respecto. Desde allí, el crecimiento ha sido exponencial, pues entre 1950 y el 2000 se escribieron 8.000 articulos. Y en los primeros 15 años del siglo XXI, ha habido 20.000 más, es decir, un aumento de 8 veces ${ }^{(3)}$.

Este trabajo de 1935 fue el primero estructurado sobre el tema, con una colección de pacientes bien estudiadas y tratadas para la época. Antes de eso, la literatura registra informes de casos. En 1721, el científico italiano Vallisneri describió el caso de una mujer casada, infertil, con ovarios brillantes de superficie blanca, del tamaño de huevos de paloma. Otro informe, según Szydlarska ${ }^{(4)}$ es de 1844, cuando Chereau y Rokitansky describieron lesiones esclerofibrosas de un carácter degenerativo en ovarios con folículos hidrópicos. Bulius y Kretschmar describieron hipertecosis por primera vez. Como sabemos, las células de la teca se encargan de la producción de andrógenos ováricos y también retoman andrógenos más débiles provenientes de las suprarrenales como la DHEA-S y los convierten en testosterona, las de la granulosa producen estrógenos (por acción de una aromatasa sobre los andrógenos), cosa que también ocurre en el tejido graso para formar estrona. Continúa la autora polaca Szydlarska ${ }^{(4)}$ : En 1879 Lawson Tait presentó la necesidad de

Figura 1. Irving F. Stein (a la izquierda) y su asociado Michael L. Leventhal (a la derecha).

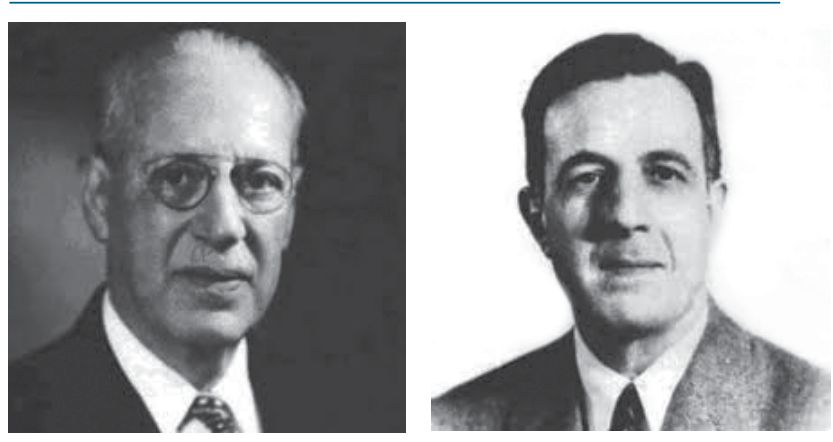


ooforectomía bilateral para el tratamiento de la degeneración quística ovárica sintomática, sugiriéndose después la resección parcial de los ovarios. En 1902 von Kahlden publicó una revisión de la patología e implicaciones clínicas de dichos ovarios. Como hubo críticos de la resección ovárica, John A. McGlinn en 1915 sugirió puncionar los quistes superficiales.

Irving Freiler Stein (1887-1976) nació y murió en Chicago, Estados Unidos. Estudió en la Universidad de Michigan y se graduó de médico en el Rush Medical College en 1912. Después de completar su internado y residencia en el Hospital Michael Reese de Chicago, hizo carrera académica en su departamento de ginecología y obstetricia hasta llegar a ser médico tratante mayor y profesor asociado emérito de Ginecologia y Obstetricia en Northwestern University. Fue presidente de la Sociedad Americana de Esterilidad. Fue miembro de varias sociedades científicas nacionales e internacionales, y durante su carrera académica publicó más de 200 trabajos sobre infertilidad y particularmente sobre el tema de los ovarios poliquísticos. Su asociado Michael Leo Leventhal (1901-1971) también nació en Chicago, estudió en la Universidad de Chicago y egresó como médico del Colegio Médico de Rush. Se entrenó y fue médico tratante en el Michael Reese, prestó sus servicios al ejército norteamericano durante la Segunda Guerra Mundial. Escribió ocho trabajos sobre el tema de los ovarios poliquísticos ${ }^{(5-7)}$. Stein y Leventhal hicieron con su trabajo un aporte significativo a la medicina, y durante años el síndrome descrito llevó sus nombres como epónimo. En el siglo XXI se ha dejado de usar para cambiarlo por el de SOP. Es posible que más adelante, cuando se conozca mejor su origen, vuelva a cambiar de nombre.

En 1990, el Instituto Nacional de Salud de los Estados Unidos (NIH) patrocinó una conferencia sobre SOP para elaborar unos criterios diagnósticos formales ${ }^{(8)}$. Un grupo posterior reunido en Rotterdam expuso nuevos criterios, más amplios (tabla 1) que incorporaron el tamaño y la morfología de los ovarios determinados por ultrasonido. Hay otros criterios de la Sociedad de Andrógenos en Exceso, que incluye la hiperandrogenemia como criterio fundamental ${ }^{(9)}$.

Después de muchas investigaciones se ha llegado a la conclusión de que el SOP es multifactorial en origen, parcialmente genético aunque los genes candidatos solo podrían explicar un $10 \%$ de los casos. Incluso - como cosa curiosa - se ha dicho
Tabla 1. Criterios diagnósticos de Rotterdam (The Rotterdam ESHRE/ASRM - Sponsored PCOS Consensus Workshop Group)

Hiperandrogenismo clínico o bioquímico: definido como un aumento de la testosterona libre o de la proteína ligadora de testosterona.

Oligomenorrea/amenorrea: Menos de ocho menstruaciones en un año o ausencia total de menstruación

Ovarios poliquísticos en ecografía: Presencia de 12 o más folículos en cada ovario con una medida entre 2 y $9 \mathrm{~mm}$ o un volumen de $10 \mathrm{ml}$.

que si hay genes involucrados, el SOP (pero sin ovarios) podría presentarse en hombres como un síndrome metabólico ${ }^{(10)}$.

La presencia de resistencia a la insulina (descrita originalmente por Reaven como síndrome X y ahora denominado síndrome metabólico) ${ }^{(11)}$ es consistente, especialmente en aquellas mujeres que tienen hiperandrogenismo. Este grupo puede presentar enfermedad cardiovascular, hipertensión, intolerancia a la glucosa o franca diabetes, e hiperlipidemia, problemas asociados con la obesidad y la hiperandrogenemia ${ }^{(12,13)}$.

El avance tecnológico facilitó los análisis hormonales que demostraron el hiperandrogenismo como mecanismo de la anovulación. Como el SOP es heterogéneo, de ahí su dificultad para definirlo; esto anticipaba la moda actual de cuestionar su existencia y aceptar la conveniencia de cambiarle de nombre o redefinirlo, dejándolo como un simple síndrome con varios fenotipos. El componente endocrino incluye secreción anormal de insulina $y$, consecuentemente, resistencia periférica a esta hormona que coexiste con hiperandrogenismo, dislipoproteinemia y obesidad.

Los exámenes hormonales a menudo son innecesarios para el diagnóstico y tratamiento; es conveniente demostrar, por ultrasonografía el crecimiento ovárico. El tratamiento debe individualizarse en relación con el motivo de la consulta y la edad de la paciente. No se ha demostrado que los sensibilizadores a la insulina eviten la enfermedad cardiovascular a largo plazo y la diabetes. Por lo tanto, el fenotipo es heterogéneo con un componente metabólico inconstante y, por ello, ha surgido la inquietud de una mejor definición del SOP.

\section{Referencias}

1. Jácome-Roca A. Historia de las Hormonas. Academia Nacional de Medicina, 2008. Pp. 115-120

2. Stein IF, Leventhal ML. Amenorrhea associated with bilateral polycystic ovaries.Am J Obstet Gynecol. 1935; 29:181-191.

3. Azziz R,Adashi EY. Stein and Leventhal: 80 years on. Am J Obstet Gynecol. 2016; 214 (2):247.e1-247.e11.

4. Szydlarska D et al. History of discovery of polycystic ovary syndrome. Adv Clin Exp Med. 2017; 26(3):555-558

5. Gardner, G.H. Dr Irving F. Stein. Q Bull Northwest Univ Med Sch. 1953; 27:368-369.

6. Powell JL. Powell's pearls: Irving Freiler Stein, MD (1887-1976) and Michael Leo Leventhal, MD (1901-1971). J Pelvic Med Surg. 2008;14:413-414.

7. Dastur AE, Tank PD. Milestones: Irving Stein, Michael Leventhal and a slice of endocrine history. J Obstet Gynecol India. 2010; 60:121-122.

8. Huang A, Brennan K, Azziz R. Prevalence of hyper-androgenemia in the polycystic ovary syndrome diagnosed by the National Institutes of Health

1990 criteria. Fertil Steril. 2010; 93 (6): 1938-1941.

9. Azziz R, Carmina E, Dewailly D et al. The Androgen Excess and PCOS Society criteria for the polycystic ovary syndrome: the complete task force report. Fertil Steril. 2009; 91:456-488.

10. Kurzrock R, Cohen PR. Polycystic ovary syndrome in men: Stein-Leventhal syndrome revisited. Med Hypotheses 2007; 68 (3):480-3.

11. Reaven GM. Insulin resistance, the insulin resistance syndrome, and cardiovascular disease. Panminerva Med. 2005; 47(4):201-10.

12. Sarafidis PA, Nilsson PM.The metabolic syndrome: a glance at its history. J Hypertens. 2006;24(4):621-6.

13. Goodman NF, Cobin RH, Futterweit W, Glueck JS, Legro RS, Carmina E; American Association of Clinical Endocrinologists (AACE); American College of Endocrinology (ACE); Androgen Excess and PCOS Society (AES). Guide To The Best Practices In The Evaluation And Treatment Of Polycystic Ovary Syndrome--Part 1. Endocr Pract. 2015;21(11):1291-300. 